\title{
BRINCADEIRAS POPULARES EM CANDIDO PORTINARI: DESCRIÇÕES DE UMA ARTE EDUCATIVA
}

\author{
Fabiane Castilho Teixeira \\ Universidade Estadual de Maringá, Maringá, Paraná, Brasil \\ Larissa Michelle Lara \\ Universidade Estadual de Maringá, Maringá, Paraná, Brasil
}

\section{Resumo}

O texto discorre sobre a iconografia de Candido Portinari a partir do subtema "Jogos infantis" (Brincadeiras), identificando quais as brincadeiras recorrentes em sua arte e o conteúdo que expressam. Para tanto, 20 temas compõem a investigação, sendo descritas 43 brincadeiras populares em seus elementos constituintes. Com isso, espera-se fomentar o diálogo entre arte pictórica e práticas educativas, favorecendo a visualização de interações possíveis e necessárias à ação pedagógica.

Palavras-chave: Brincadeiras Populares. Educação. Arte.

\section{Introdução}

\begin{abstract}
A apropriação da arte no contexto educacional propicia ampla formação dos diferentes atores sociais ao requerer o entendimento de seu caráter contestador, de sua racionalidade estético-expressiva e de sua finalidade sem fim. Isso porque o conhecimento da arte, ao mesmo tempo em que se encerra em si mesmo, em sua dimensão estética e, portanto, de fruição e experiência, transcende essa intencionalidade rumo ao potencial crítico e interventor. Por vezes, a arte se configura como retrato de realidades e mazelas às quais o ser humano é submetido, convertendo-se em formas de crítica dos mecanismos de exploração e dominação, bem como em formas culturais locais ou mundiais expressivas na sua cotidianidade.

A arte do brasileiro Candido Portinari ${ }^{1}$ (1903-1962) revela aspectos centrais da cultura brasileira, como o oprimido, as manifestações cul-

1-Filho de modestos imigrantes italianos, Candido Portinari nasceu em 29 de dezembro de 1903, em Brodósqui (SP). Estudou na Escola Nacional de Belas-Artes, no Rio de Janeiro (RJ), quando começou a se destacar por seus retratos. A preocu-
\end{abstract}


turais populares, os jogos e brincadeiras, o trabalhador, favorecendo o reconhecimento de um Brasil com muitas nuanças. São temas históricos, sociais, religiosos e de representação da cultura brasileira. Sua arte evoca sensibilidade e reflexão, configurando-se como elemento educacional por possibilitar leituras não unilaterais, capazes de instigar aprendizados pautados em campos interpretativos diversos, próprios do humano e de sua capacidade crítica.

As obras de Portinari desenvolvidas nesse tema propiciam reflexões sobre a arte do brincar, do jogar desobrigadamente, sem o viés competitivista que impera na sociedade da instrumentalização do outro e da razão. O instante lúdico presente nas telas, o corpo que brinca, joga e cria um tempo-espaço próprio, a condição do ser criança e a potencialidade criadora favorecem aprendizados singulares a serem potencializados na prática educativa.

A incursão pelas produções artísticas de Candido Portinari ocorreu mediante investigação de telas que tematizam a "Cultura brasileira" e que caracterizam o subtema "Jogos infantis", particularmente, a categoria "Brincadeiras". O conceito de brincadeira é aqui entendido na perspectiva desenvolvida por Caillois (1986) como aquela que se aproxima do divertimento, da turbulência, da improvisação livre e da fantasia incontrolada, ou seja, da paidia, contrariamente ao ludus que conduz à obediência às regras, aos desafios para alcance de resultados, entendimento próprio do jogo. Dado o fato de a maioria das telas pintadas nesse subtema revelar a fantasia, a criação e a entrega atemporal, adotaremos a terminologia brincadeiras para menção a essa iconografia.

Uma vez que há inúmeras telas associadas às "Brincadeiras", optamos, nesta pesquisa, pelo estudo do conteúdo de obras que apresentas-

pação do artista com a temática social brasileira acentuou-se em 1939, quando criou três grandes painéis para o pavilhão brasileiro na exposição internacional de Nova York. A década de 1940 é marcada pela série dos Retirantes, com personagens esquálidos, famélicos e maltrapilhos como Enterro na rede e Menino morto. As telas A chegada de São João VI, Guerra e paz e Retirantes foram pintadas em 1950. Nessa mesma década, Portinari realiza para O Banco Português do Brasil o painel Descobrimento do Brasil. Ainda nesse período, no ano de 1954, tem os primeiros sintomas de intoxicação pelas tintas. Em 1962 Portinari morre, vítima da uma hemorragia decorrente da toxidade dos produtos que usava para expressar sua arte.

Pensar a Prática, Goiânia, v. 15, n. 3, p. 551-820, jul./set. 2012 
sem formas gestuais que denotassem movimento e expressão. Daí terem sido analisados 19 temas de brincadeiras populares e um tema denominado "Outras obras" (conglomerado de brincadeiras). Escolhemos de uma a três obras de cada tema com base em critérios como: formas gestuais, diversidade no brincar e suficiência investigativa. Em tema composto por duas telas, apresentando arte de brincar semelhantes, apenas um era escolhido, pois já atendia aos objetivos elencados. Em temas que apresentassem grande quantidade de telas, a seleção dava-se respeitando o número limite estabelecido para a pesquisa por tema, a clareza na representação das formas gestuais e a presença de formas diferenciadas do brincar ${ }^{2}$.

Para o desenvolvimento investigativo foi escolhido o método iconológico, que consiste em três etapas, de acordo com Panofsky (1979): a) pré-iconografia, caracterizada pela identificação dos motivos artísticos e experiência empírica; b) iconografia, que busca a descrição das imagens, histórias e alegorias, relacionando-as a fontes literárias; c) fase iconológica, constituída pela síntese a partir do mundo de valores simbólicos. Desse modo, o tratamento dos dados da pesquisa foi realizado mediante as técnicas próprias da iconologia, que se traduzem pela focalização das informações ligadas diretamente às categorias elegidas (acima relacionadas), pelas descrições, interpretações e análises das telas feitas pelas pesquisadoras, bem como pela relação estabelecida com a literatura no que se refere ao brincar, ao corpo e à ludicidade.

Dada a quantidade de obras analisadas, o texto volta-se para o reconhecimento de jogos infantis que foram tematizados por Portinari em suas telas e para a descrição de seus elementos constituintes. $\mathrm{O}$ intuito foi identificar essa arte e seu conteúdo no sentido de favorecer a percepção de interações possíveis e necessárias com a prática pedagógica.

\section{Brincadeiras populares em Candido Portinari}

As telas de Candido Portinari selecionadas para esta pesquisa fazem parte do acervo do Projeto Portinari, site em que são disponibili-

2-Vale observar que a escolha não foi simples em alguns temas, a exemplo de "Brincando na gangorra", que apresenta 23 obras de Portinari. Em casos como esse, prevaleceu a percepção do pesquisador e sua experiência estética acerca de obras que atendiam mais diretamente aos critérios elegidos. 
zadas diversas obras do artista, organizadas por temas ${ }^{3}$. As telas sobre brincadeiras populares foram selecionadas com base nas dimensões do brincar, do corpo e da ludicidade expressas por Portinari. Dos 20 temas sobre brincadeiras infantis, 43 obras foram selecionadas para análise. Segue o Quadro 1, com os temas das brincadeiras populares encontrados em Candido Portinari ${ }^{4}$.

\begin{tabular}{|l|l|}
\hline \multicolumn{2}{|c|}{ BRINCADEIRAS POPULARES } \\
\hline 1. Atirando com estilingue & 11. Jogando futebol \\
\hline 2. Brincando de cabra-cega & 12. Malhando Judas \\
\hline 3. Brincando de diabolo & 13. Plantando bananeira \\
\hline 4. Brincando de roda & 14. Pulando amarelinha \\
\hline 5. Brincando na gangorra & 15. Pulando carniça \\
\hline 6. Brincando no balanço & 16. Pulando corda \\
\hline 7. Dando cambal hota & 17. Rodando arco \\
\hline 8. Empinando pipa & 18. Rodando pião \\
\hline 9. Equilibrando varas & 19. Soltando balão \\
\hline 10. Jogando bola de gude & 20. Outras obras \\
\hline
\end{tabular}

Quadro 1: Temas de brincadeiras populares retratadas por Candido Portinari

Das oito telas pintadas acerca da temática "Atirando com estilingue", selecionamos três, que são: a) Briga de cachorros; b) Menino com estilingue; c) Meninos com estilingue. Atzingen (2001) esclarece que no período neolítico ( 8000 a 4000 a.C.) o homem já utilizava estilingues ou atiradeiras para lançar bolas de argila e pequenas pedras. Alguns estilingues, datados de 6500 a.C., foram encontrados em sítios arqueológicos na Turquia.

As três imagens pintadas por Portinari sobre esse tema apresentam cores, linhas e formas diversificadas. Em uma delas (Briga de cachorros), pintada em preto e branco, no ano de 1957, observamos uma brincadeira que envolve crianças e animais. Os meninos representados parecem empregar o próprio estilingue para tentar separar a briga entre cachorros, que ocorre na rua. Já a tela colorida Menino com estilingue, de 1958, traz um menino negro que, sentado em uma grande

3-O acervo do Projeto Portinari (endereço eletrônico: http://www.portinari.org.br/index.htm) compreende o levantamento e a catalogação de quase 5.000 obras e aproximadamente 30.000 documentos a elas relacionados, como correspondências, recortes de periódicos, livros, fotografias, depoimentos, entre outros.

4-Temas elencados pelo Projeto Portinari, disponíveis em http://www.portinari.org.br/index.htm. Acesso em: 11 fev. 2007. 
pedra, prepara seu próprio brinquedo. Em Meninos com estilingue há crianças brincando em espaço fechado. É uma tela de 1959, com traços cubistas ${ }^{5}$, peculiaridade da obra de Candido Portinari.

No que diz respeito ao tema "Brincando de cabra-cega", das três obras pintadas selecionamos duas, por apresentarem conteúdos diferentes. São elas: a) Crianças brincando; b) Jogos infantis. A primeira tela, pintada em 1957, traz crianças em cenário similar a um parque. Algumas se encontram em brinquedos, como a gangorra; outras estão dispersas no local, sendo pintadas a partir do movimento de seus corpos, com braços ao alto, giros e pés batendo no chão. A segunda obra, datada do ano de 1944, é uma tela abstrata, com figuras representadas em meio a elementos geométricos. No século XVI, em Portugal, assegura Melo (1985), já se brincava de cabra-cega com o nome de almolina. A difusão da cabra-cega é grande na América Latina, sendo chamada, no Chile, de el gallo descasbezado; na Argentina, são várias denominações: gallo ciego, gallito ciego, gallinita ciega.

Para o tema "Brincando de diabolô", das duas obras existentes selecionamos apenas uma - Menino com diabolô -, por considerarmos que ambas são similares em suas formas gestuais. O menino representado na referente obra aparece segurando o diabolô com os braços para o alto, olhando atentamente para cima, de modo a não deixar cair o carretel. É uma criança negra e se encontra brincando sozinha. A obra foi pintada em 1955.

Compõem o tema "Brincando de roda" 13 obras, tendo sido selecionadas: a) Dança de roda; b) Ciranda na praça de Brodowski. Em uma das telas (Dança de roda), datada de 1955, a brincadeira parece ser de adultos e contempla mulheres negras dançando. Já Ciranda na praça de Brodowski, pintada em 1932, apresenta pessoas brincando ao ar livre e revela parte da cidade em que Portinari viveu sua infância, com as casas e a igreja ao fundo da tela.

Tratando-se do tema "Brincando na gangorra", das 23 obras pintadas selecionamos três, sendo elas: a) Gangorra (1937); b) Meninos na gangorra (1960); c) Palhacinhos na gangorra (1957). Embora Portinari tenha realizado as pinturas em períodos diferentes, os personagens aparecem na parte superior da gangorra sempre com os braços ao alto,

5-O cubismo é um movimento artístico do princípio do século XX, caracterizado pela análise das formas dos objetos e sua representação, decompostos em elementos geométricos simples, sem reconstituição da perspectiva.

Pensar a Prática, Goiânia, v. 15, n. 3, p. 551-820, jul./set. 2012 
como se brincassem com prazer, livres e sem medo. Características similares puderam ser observadas nas três obras apresentadas, com o diferencial que uma delas traz palhacinhos numa gangorra aparentemente isolada no campo. Como afirma Atzingen (2001), a ideia da gangorra surgiu na Grécia Antiga, onde as crianças passavam uma corda por um tipo de roldana presa a um galho de árvore e, segurando-se em suas extremidades, forçavam que, com seu peso, um dos participantes subisse e descesse. A gangorra, ou balance, como é conhecida em Portugal, esteve em moda na Europa durante o século XVI.

Das 16 obras pintadas sobre a temática "Brincando no balanço" selecionamos três, que são: a) Meninos no balanço; b) Criança brincando; e c) Meninos brincando no balanço. $\mathrm{Na}$ imagem Meninos no balanço, datada de 1955, temos crianças conversando e balançando lentamente. A obra expressa a melancolia, sendo essa característica demonstrada por meio da própria pintura que se revela fosca e opaca. Diferentemente, a tela Criança brincando, de 1955, traz uma criança sozinha. Portinari demonstra o movimento de seu brincar, que se dá em meio a um campo aberto, revelando sentimentos de paz e tranquilidade. Já a pintura Meninos brincando no balanço, datada de 1960, em que as crianças se balançam desordenada e altivamente, é colorida, com traços cubistas. Segundo Atzingen (2001), em muitos lugares o balanço manteve um valor simbólico e religioso, associado às ideias de chuva, renovação da natureza e fecundidade.

Também foram selecionadas, entre dez telas de Portinari, três que correspondem ao tema "Dando cambalhota": a) Cambalhota; b) Paz; c) Menino com carneiro. A tela Cambalhota, produzida em 1958, apresenta duas crianças: uma delas faz a parada de mãos (popularmente conhecida como bananeira), enquanto a outra demonstra empenho ao girar o corpo apoiado em apenas uma das mãos. Na obra Paz, de 1955, o pintor reúne várias cenas no mesmo espaço. São crianças no balanço, em brincadeiras de roda, na gangorra e dando cambalhotas. Há um grupo que se encontra reunido como se estivesse cantando em um coral, ao passo que meninos caminham com crianças menores nos ombros. A presença de animais junto com pessoas é um traço nitidamente visível nas obras do pintor. Como exemplo temos a obra Menino com carneiro, criada no ano de 1960, sendo representada por um menino fazendo rolamento com apenas uma das mãos apoiada no chão e com um carneiro à sua frente, observando-o. 
A temática "Empinando pipa" agrega 46 obras. Destas, três foram selecionadas: a) Brodowski; b) Menino soltando pipa; c) Meninos soltando pipas. Como relata Atzingen (2001), as pipas apareceram na China 1000 anos a.C. e, antes de serem brinquedos, eram dispositivos de sinalização militar, cuja cor, padrão da pintura e movimentos no ar comunicavam códigos de mensagens entre os campos. No Brasil, a pipa chegou com os portugueses e há notícias de que foi usada por sentinelas, no Quilombo dos Palmares, também como sinalizadora de perigos.

A tela Brodowski, produzida no ano de 1942, remete a crianças empinando suas pipas em uma estrada na referida cidade, provavelmente de pouco movimento, permitindo às crianças correrem livremente. Enquanto a pintura em si mostra-se sombreada, o pintor usa cores fortes para destacar as pipas. Menino soltando pipa, obra datada de 1956, traz um menino de costas soltando pipa, sozinho. O pintor não se utiliza de muitos elementos nessa imagem, desenhando somente o menino, a pipa e o chão. Já a tela Meninos soltando pipas, de 1952, retrata alguns meninos soltando pipas, interceptando-as e conversando entre si.

Das duas obras existentes que identificam o tema "Equilibrando varas", selecionamos apenas uma, por considerarmos que ambas são similares, tanto em cores, linhas e formas, quanto no conteúdo. A referida obra (Meninos brincando com varas), criada em 1959, é a ilustração original n.7 do livro Menino de engenho, de José Lins do Rego. $\mathrm{Na}$ imagem, os traços e as formas dos sujeitos são explícitos, assim como a expressão de seus rostos, sendo caracterizada por adolescentes brincando, na rua, de equilibrar varas.

Existem duas obras com o tema "Jogando bola de gude", que são: a) Crianças brincando; e b) Meninos brincando. Conforme Atzingen (2001), povos primitivos faziam as bolinhas com pedra, argila, madeira ou osso de carneiro, sendo que, na Grécia, as crianças também jogavam com castanhas e azeitonas e, em Roma, com nozes e avelãs. As mais antigas já encontradas são as de pedras semipreciosas e estavam no túmulo de uma criança egípcia, de 3000 a.C. Na ilha de Creta foram encontradas bolinhas feitas com pedras polidas de jade e ágata, datadas de 1450 a.C.

Crianças brincando, datada de 1957, apresenta crianças se divertindo por meio da prática de diferentes brincadeiras, sendo elas: empinar pipas, brincar na gangorra, correr, girar e jogar bola de gude. A obra é 
pintada em preto e branco e evidencia o contentamento entre os brincantes. A tela Meninos brincando, criada em 1955, também traz crianças exercendo mais de uma brincadeira: algumas dão cambalhotas, outras se equilibram, e dois meninos aparecem brincando de bola de gude. Nessa imagem, Portinari novamente situa um animal entre as crianças, apontando que, nesse período e nessa comunidade, era comum o brincar em meio aos animais.

O tema "Jogando futebol" contempla 18 telas, sendo três as selecionadas: a) Futebol; b) Jogando futebol; e c) Praça de Brodowski. A obra Futebol é de 1958; nela, há várias crianças brincando, num grande grupo. Porém, seus rostos estão desfigurados na pintura. Mesmo sem a percepção da expressão da face, o elemento lúdico se coloca presente. O jogo ocorre em campo bem extenso, próximo a algumas casas que se revelam presentes ao fundo da tela. Em Jogando futebol, pintada em 1939, em preto e branco, temos dois grupos de meninos jogando futebol, sendo que um deles se prepara para receber a bola. A brincadeira parece ocorrer em dia ensolarado, pois na pintura aparece a sombra das crianças. Na tela Praça de Brodowski, datada de 1939, o pintor traz cores escuras, predominando o tom marrom. Os garotos brincam em local recoberto por árvores, com a presença de um animal que não aparece interferir na brincadeira. Como lembra Bruhns (2000), o futebol desenvolveu-se historicamente e foi conquistando seu lugar na sociedade brasileira, transitando por várias classes sociais e caracterizando-se, enfim, como manifestação típica de nossa cultura, principalmente das camadas desfavorecidas.

Portinari produziu três obras com a temática "Malhando Judas", sendo elas: a) Malhando Judas; b) Judas; c) Malhando Judas. A pintura Malhando Judas, de 1957, mostra quatro pessoas batendo com força contra um boneco. Elas possuem, nas mãos, um objeto semelhante a um bastão. Há também, entre elas, animais, sendo um cachorro e um gato. Enquanto todos da imagem se encontram concentrados em executar a tradição, o gato olha de modo agressivo e fixo para fora da pintura. São perceptíveis na obra Judas, de 1943, roupas remendadas e tamanhos desproporcionais do corpo, imagem que retrata o boneco a representar Judas Iscariotes. Ele se encontra amarrado em uma vara de madeira, preso pela cintura e pescoço com uma corda (lembrando que o traidor de Jesus se enforcou após a traição). A obra Malhando Judas, de 1940, apresenta muitas pessoas com bastões em suas mãos malhando Judas no período da noite, contrariando a tradição que relata que 
esse costume é realizado ao meio-dia. A Malhação de Judas ou Queima de Judas é uma tradição vigente em diversas comunidades católicas e ortodoxas, introduzida na América Latina pelos espanhóis e portugueses.

Existem 12 obras produzidas por Portinari acerca da temática "Plantando bananeira", sendo duas pinturas selecionadas: a) Cambalhota; b) Menino plantando bananeira. Plantar bananeira é expressão comum para a técnica de ficar de cabeça para baixo, com o peso do corpo apoiado nas mãos e as pernas para cima. A pintura Cambalhota, do ano de 1955, exibe dois garotos plantando bananeira no solo. Um deles é retratado apoiando o corpo com a cabeça e as mãos, tentando equilibrar-se; o outro apoia seu corpo apenas com uma das mãos e está inclinado. $\mathrm{O}$ destaque, na obra Menino plantando bananeira, do ano de 1940, dá-se ao menino que projeta seu corpo de cabeça para baixo apoiado pelas mãos e pela cabeça, à frente da pintura. Ao fundo são representadas mulheres de branco que, provavelmente, dançam durante a noite, uma vez que é possível perceber a lua iluminando o local.

As obras criadas sobre a temática "Pulando amarelinha"6 são cinco, tendo sido selecionadas duas: a) Gangorra e amarelinha; b) Paz. A amarelinha é um jogo antigo, praticado até hoje em muitos países e parte do folclore brasileiro. Nas palavras de Atzingen (2001), a amarelinha tradicional tem o formato de uma cruz com um semicírculo em uma das pontas, em que está a palavra céu, lua ou cabeça. A obra Gangorra e amarelinha é um desenho em preto e branco, criado em 1937, com dois personagens brincando na gangorra. $\mathrm{O}$ que está no alto encontra-se com as mãos soltas do brinquedo, enquanto outras duas crianças estão à volta sem desenvolver atividade alguma. Ao fundo da imagem está uma garotinha brincando sozinha em uma amarelinha desenhada no chão. Já a obra Paz exibe manifestações diversificadas de brincadeiras populares. Produzida entre 1952 e 1956, foi executada para decorar a sede da Organização das Nações Unidas (ONU). Há contraste entre as pessoas, as atividades e o fundo da tela, como a mistura de adultos com crianças, homens e animais. Todos estão se divertindo, brincando, "em paz". Ao centro da tela podemos observar uma roda formada por mulheres e brincadeiras na gangorra, no balanço e

6-Na temática "Pulando amarelinha", a tela Paz apresenta nome idêntico ao da segunda obra da temática "Dando cambalhota". Isso ocorre em outras telas pintadas por Portinari, que atribui o mesmo nome a obras de temas distintos.

Pensar a Prática, Goiânia, v. 15, n. 3, p. 551-820, jul./set. 2012 
no solo. Há meninos virando cambalhota, mulheres se equilibrando com apenas um pé, pessoas dançando e crianças próximas umas das outras.

Das 34 obras pintadas por Portinari sobre a temática "Pulando carniça", também conhecida por pular cela ou leap frog, selecionamos três, que são: a) Menino; b) Moleques pulando cela; c) Pulando carniça. A obra Menino, produzida em 1950, apresenta um menino na fase do salto, com as mãos e as pernas estendidas. A pintura não traz a pessoa ou o objeto sobre o qual o menino estaria saltando, mas caracteriza a brincadeira, que consiste em dar saltos. Diferentemente da obra anterior, Moleques pulando cela, de 1958, traz a brincadeira de forma nítida, com dois meninos negros brincando num ambiente aparentemente vazio. Os garotos apresentam os mesmos traços físicos e usam roupas semelhantes. Já na pintura Pulando carniça, de 1959, Portinari representa crianças brincando num espaço aberto, em que a natureza é explicitamente focalizada a partir de matas, montanhas e riachos. Pessoas aparecem ali como se estivessem conversando ou até mesmo observando a brincadeira dos meninos.

O tema "Pulando corda" contém apenas uma obra que o identifica, denominada Jogos infantis. A brincadeira de pular corda ocorre com pessoas sozinhas ou em grupo. É permitido pular para frente, para trás ou dar a volta na corda. A tela pintada por Portinari em 1941 traz variadas maneiras de brincar. Uma delas está representada por crianças, possivelmente meninas, uma vez que os personagens são retratados vestindo vestidos e aparecem brincando de mãos dadas. Em outra, dois garotos jogam bola e, mais ao fundo, duas crianças brincam de pular corda.

Para o tema "Rodando arco" também há apenas uma obra, intitulada Praça de Brodowski. Rodar arco é o nome dado a uma das mais antigas brincadeiras de rua e consiste em fazer rolar um arco pela rua afora, dirigindo-o com um bastão. Conforme os estudos de Atzingen (2001), a brincadeira com o arco existe há tanto tempo quanto a roda, mas só após o fim do século VI a.C. é que a história conta sua presença na Grécia Antiga, onde o arco era usado como instrumento de ginástica ou de exercício das pessoas com problemas de debilidade física. A obra pintada por Portinari é de 1956 e traz uma praça composta por vários elementos. É a praça da infância de Portinari, no interior paulista. Percebemos animais transitando pelo local, pessoas prestigiando a apresentação de um palhaço que monta num burro, 
imagem do circo e da igreja, vilarejo representado junto à natureza e, como figura principal, o menino que aparece rodando o arco.

Das cinco obras pintadas acerca da temática "Rodando pião", selecionamos uma: a) Crianças jogando pião na praça de Brodowski. O pião, escolhido como tema por Portinari, é um brinquedo de madeira, piriforme, com uma ponta de ferro sobre a qual o objeto gira. É impulsionado pela fieira, que deve ser puxada com firmeza e habilidade. Como observa Atzingen (2001), em 3000 a.C., na Babilônia, já existiam os piões, feitos de argila e com as bordas decoradas, com formas animais e humanas, ou relevos, encontrados em túmulos de crianças. $\mathrm{Na}$ obra Crianças jogando pião na praça de Brodowski, em preto e branco, datada de 1933, há garotos brincando numa praça, dispostos em roda para rodopiarem os piões. É possível perceber o movimento de seus corpos, a gestualidade e, até mesmo, a expressão de suas faces, com demonstração de euforia e nervosismo. A igreja, novamente, aparece na praça de Brodósqui, o que nos leva ao entendimento de que era componente daquela localidade. Há, também, a figura de um adulto que, como mostra a imagem, inseriu-se no local no sentido de participar da brincadeira.

O tema "Soltando balão" conta com duas imagens selecionadas, das 12 existentes, que são: a) Marinha; b) Três Marias. Antigamente, na cultura brasileira, o balão fazia parte das brincadeiras populares das crianças, sendo hoje considerado crime o fato de um balão cair aceso em florestas, residências e indústrias, produzindo prejuízos patrimoniais e ambientais. A obra Marinha, de 1942, traz a praia como cenário, com mar e grandes ondas, montanha (com inúmeros pássaros sobrevoando-a) e barco navegando. Ao fundo da tela há mais montanhas e, em meio à areia, uma criança com os braços ao alto soltando balões. Já Três Marias, criada em 1940, retrata três mulheres negras que se encontram soltando balões e pipas, com os braços ao alto. Demonstram observar os objetos com os quais aparecem brincando. Há também um homem subindo num pau-de-sebo.

São 13 as imagens da temática "Outras obras". Entre elas, selecionamos as seguintes: a) Catando gabiroba; b) Pai brincando com filho. A obra Catando gabiroba, produzida em 1957, apresenta pessoas coletando esse fruto que cresce nos campos e pastagens do cerrado brasileiro. O local onde as pessoas estão inseridas possui uma cerca, o que indica ser propriedade privada. É possível identificar debaixo das árvores a presença de um boi próximo às crianças que estão colhendo a 
fruta. Já a pintura Pai brincando com filho, de 1960, retrata a relação entre pais e filhos, em que está expresso o sentimento de amor. $\mathrm{Na}$ obra de Portinari, o pai está deitado no chão, com pernas flexionadas e braços para o alto. $\mathrm{O}$ filho dá suas mãos ao pai e apoia os pés em seus joelhos. A maneira como eles estão, com a criança projetada acima do pai, demonstra a confiança existente entre ambos.

Em síntese, as obras de Portinari que tratam das brincadeiras infantis revelam a cultura lúdica presente no cotidiano da realidade brasileira, análise decorrente de olhares atenciosos mesclados a percepções próprias e a estudos realizados em literatura que tratam do tema de investigação. A atividade do brincar é, como lembra Santin (1995), o fenômeno mais eloquente da unidade do ser humano e a maior denúncia dos dualismos. O indivíduo que brinca vivencia uma simbologia que o seu imaginário vai inspirando. Na imaginação que se traduz na brincadeira, o corpo se apresenta não submisso ao pensamento ou à razão, mas segue livremente os labirintos da arquitetura imaginária que o transforma numa entidade simplesmente lúdica e somente lúdica.

\section{Pelas descrições, algumas considerações}

As brincadeiras populares em Candido Portinari foram investigadas no sentido de identificar quais eram recorrentes e que conteúdos expressavam, favorecendo a visualização de interações possíveis e necessárias entre arte pictórica e ação pedagógica. As descrições de elementos constitutivos das 43 obras selecionadas para análise possibilitaram reflexões sobre a pintura de Portinari como fonte educacional e como meio de despertar a racionalidade estético-expressiva nem sempre valorizada como forma de conhecimento, ou seja, nem sempre potencializada como meio de aprendizado, de experiência estética, de percepção necessária à educação do humano.

Tematizadas por Candido Portinari, as brincadeiras populares trazem formas diversas da cultura do corpo, como brincar de roda, gangorra, balanço, cambalhota, pipa, bolas de gude, amarelinha, arco, pião, balão, entre outras. Algumas formas do brincar ocorrem mediante o objeto (brinquedo) que constitui o elemento gerador da ação propriamente dita e da rede de sociabilidade criada em torno dele. É o estilingue que proporciona a brincadeira do atirar para acertar o alvo; é a gangorra que favorece o subir e descer, o frenesi da perda do contato com o solo, a vertigem necessária; é o arco que potencializa a co- 
ordenação, o desafio de manter o objeto contra a gravidade, entre tantas formas possíveis.

As telas aqui apresentadas e discutidas foram produzidas pelo pintor com base em sua infância na cidade de Brodósqui, revelando as manifestações culturais que constituíram determinada época. Vilarejos, personagens diversos, animais, igrejas, praças, natureza, são alguns dos elementos observados nas obras e que demonstram como sua produção é um registro cultural da memória de uma realidade local. Há nas obras de Portinari ligação entre o corpo que brinca e o cenário no qual ele se expressa. Não é um corpo amorfo, uma vez que o artista sempre o coloca em destaque, ora marcado por expressões de euforia, ora não delineado facialmente e/ou caracterizado por deformações de pés e mãos (sempre exagerados). Há tons nostálgicos que compõem o cenário e que ampliam a percepção do corpo que brinca, desse corpo lúdico sempre presente nas obras aqui analisadas. Assim, tais elementos configuram a arte própria de Portinari, colocando-se como densa fonte educacional de um brincar não engendrado nas molduras formatadas da indústria da diversão, contribuindo diretamente com o estudo do brincar junto ao contexto da educação.

Nas obras de Portinari, o corpo lúdico é o corpo que brinca (sujeito), vivenciando uma simbologia aguçada em seu mundo de fantasia. $\mathrm{Na}$ imaginação traduzida em brincadeira, o corpo demonstra ter condições de não se submeter às regras e prescrições que regem o meio, mas de agir livremente, em busca de concretizar as ações próprias dos personagens, caracterizando, dessa forma, uma identidade lúdica que, em outras situações, dificilmente poderia ser potencializada.

Ao compreendermos que a cultura do corpo pode ser apreendida por meio da pintura em telas é que as brincadeiras em Portinari, bem como o valor do brincar realçado em suas obras, fazem-se relevantes à pratica pedagógica. Nesse sentido, partimos do entendimento de que o brincar não pode ser compreendido como mera ação desprovida de conhecimento. Trabalhada em diferentes espaços sociais, a brincadeira, quando ordenadamente trabalhada, contém sentido diferente do vivenciado de modo livre na rua, pois conta com a ação pedagógica mediadora do professor, o qual traz o conteúdo de ensino, desenvolvendo-o juntamente com as crianças.

A produção artística de Candido Portinari possui recheadas possibilidades de trabalho, não se limitando às obras trazidas nesta investigação. Os temas geradores (criados a partir do tema "Obras de 
Portinari", por exemplo) inspiram caminhos diversos de aprendizado, seja com ênfase no contexto histórico em que as obras foram pintadas ou nas questões de ordem social e étnica que envolvam preconceitos, política e economia. Essa peculiaridade faz da arte do pintor, além de expressão imagética sensível, fonte histórico-documental de localidade da vida cultural brasileira, sendo seu trabalho rico material pedagógico para a formação e intervenção educacionais.

\title{
Popular play in Candido Portinari: descriptions of an art education
}

\begin{abstract}
This paper is about the iconography of Brazilian painter Candido Portinari with the sub-theme Children's Play (Kidding), identifying the recurring play in his art and the contents they express. For this purpose, 20 subjects make up the research and 43 pieces of popular play were selected, with descriptions of its constituent elements. With this, we hope to foster to the dialogue between pictorial art and educational practices, favoring the viewing of the possible interactions and necessary to the pedagogical action.
\end{abstract}

Keywords: Popular Play. Education. Art.

\section{Juegos populares en Candido Portinari: descripción de un arte educativa}

\section{Resumen}

Ese texto describe sobre la iconografía del pintor brasileño Candido Portinari con el sub-tema Juegos de los niños y identifica los juegos que son recurrentes en su arte y el contenido que ellos expresan. Así, 20 temas constituyen la investigación, con descripciones de 43 juegos populares en sus elementos constitutivos. Con esto se espera contribuir para el diálogo entre el arte pictórico y las prácticas educativas, favoreciendo la visualización de interacciones posibles y necesarias para la acción pedagógica.

Palabras clave: Juegos Populares. Educación. Arte.

\section{Referências}

ATZINGEN, M. C. V. História do brinquedo: para as crianças conhecerem e os adultos se lembrarem. São Paulo: Alegro, 2001.

BRUHNS, H. Futebol, carnaval e capoeira: entre as gingas do corpo brasileiro. Campinas: Papirus, 2000.

CAILLOIS, R. Los juegos y los hombres: la máscara y el vértigo. México: Fondo de Cultura Económica, 1986. 
MELO, V. de. Folclore infantil: acalantos, parlendas, adivinhas, jogos populares e cantigas de roda. Belo Horizonte: Itatiaia, 1985. (Biblioteca de Estudos Brasileiros, v. 20).

PANOFSKY, E. O sentido das artes visuais. Trad. Maria Clara F. Kncese. 2. ed. São Paulo: Perspectiva, 1979.

SANTIN, S. Educação física: ética, estética, saúde. Porto Alegre: Edições Est., 1995.

Recebido em: 05/07/2011

Revisado em: 12/09/2011

Aprovado em: 23/11/2011

Endereço para correspondência

faby_c.teixeira@hotmail.com

Fabiane Castilho Teixeira

Universidade Estadual de Maringá.

v. Colombo, 5790

Campus Universitário - Dep. de Educação Física

Zona 7

87020-900 - Maringa, PR - Brasil 